University of Nebraska - Lincoln

DigitalCommons@University of Nebraska - Lincoln

Faculty Publications, Department of Psychology

Psychology, Department of

2009

\title{
An Investigation of the Behavioral Mechanisms of Antipsychotic Action Using a Drug-Drug Conditioning Paradigm
}

\author{
Ming Li \\ University of Nebraska-Lincoln, mli2@unl.edu \\ Wei He \\ University of Nebraska-Lincoln \\ Alexa Mead \\ University of Nebraska-Lincoln
}

Follow this and additional works at: https://digitalcommons.unl.edu/psychfacpub

Part of the Psychiatry and Psychology Commons

Li, Ming; He, Wei; and Mead, Alexa, "An Investigation of the Behavioral Mechanisms of Antipsychotic Action Using a Drug-Drug Conditioning Paradigm" (2009). Faculty Publications, Department of Psychology. 410.

https://digitalcommons.unl.edu/psychfacpub/410

This Article is brought to you for free and open access by the Psychology, Department of at DigitalCommons@University of Nebraska - Lincoln. It has been accepted for inclusion in Faculty Publications, Department of Psychology by an authorized administrator of DigitalCommons@University of Nebraska - Lincoln. 
Original article

\title{
An Investigation of the Behavioral Mechanisms of Antipsychotic Action Using a Drug-Drug Conditioning Paradigm
}

\author{
Ming Li (mli2@unl.edu), Wei He and Alexa Mead
}

Antipsychotic drugs at noncataleptic doses selectively suppress conditioned avoidance response in rats. In our previous study, we had used a two-way active avoidance response paradigm to show that the antipsychotic-induced interoceptive state is one of the mechanisms underlying the avoidance-disruptive effect of antipsychotics. In this study, we sought to further examine this mechanism using a novel drug-drug conditioning procedure. We made use of the fact that both the typical neuroleptic haloperidol and the atypical neuroleptic olanzapine disrupt conditioned avoidance responding, whereas chlordiazepoxide (an anxiolytic) does not. We reasoned that if the antipsychotic interoceptive state is important in causing a disruption on avoidance responding (an index of antipsychotic efficacy), pairing chlordiazepoxide (a cueing drug conditional stimulus) with haloperidol or olanzapine (a cued drug unconditional stimulus) should engender chlordiazepoxide to exhibit this property and behave like an antipsychotic drug. Chlordiazepoxide exhibited an acquired antipsychotic-like property in disrupting avoidance responding after being repeatedly paired with haloperidol, but not with olanzapine. In contrast, it significantly attenuated the antiavoidance efficacy of olanzapine but not haloperidol after being repeatedly paired with these drugs. This study suggests that the haloperidol-induced interoceptive drug state is directly involved in its antiavoidance action, and chlordiazepoxide may attenuate the antiavoidance efficacy of antipsychotics (especially olanzapine). To the extent that the antiavoidance effect predicts clinical effects of antipsychotic treatment, this study suggests that the antipsychotic-induced interoceptive drug state may be an important behavioral mechanism mediating the clinical effects of antipsychotic treatments.

Keywords: antipsychotic drugs, chlordiazepoxide, conditioned avoidance response, drug-drug conditioning, polypharmacy, psychotherapeutic drug-drug interaction, rat, schizophrenia

Received October 31,2008; accepted as revised February 17, 2009.

\section{Introduction}

Antipsychotic drugs (APDs) are effective in the treatment of positive symptoms of schizophrenia (Lieberman et al., 2005). Research over the years has shown that actions at various receptor sites, notably dopamine $\mathrm{D}_{2}$, serotonin $5-\mathrm{HT}_{2 \mathrm{~A}}$, and $5-\mathrm{HT}_{1 \mathrm{~A}}$ receptors, are critically important for the therapeutic effect of both typical and atypical drugs (Seeman, 2000; Kapur and Mamo, 2003; Richtand et al., 2007). It is still not well understood how this action at the neurobiological level translates into symptom improvement. This situation is peculiar given the fact that schizophrenia is a cluster of psychological symptoms, and the diagnosis and symptom improvement all manifests at the psychological level. The neurobiological level of explanations of antipsychotic action alone is clearly insufficient to account for the clinical effect of antipsychotic action (Miller, 1987; Kapur, 2003). To understand fully how antipsychotics work, a detailed understanding of the behavioral mechanisms of antipsychotic action is needed.
We recently took a preclinical approach and investigated this issue using a well-established preclinical animal model of antipsychotics-conditioned avoidance response (CAR) model (Li et al., 2007, 2009; Mead and Li, in press). All currently available antipsychotics, at clinically relevant doses, selectively disrupt avoidance responding to a conditional stimulus (CS, e.g. white noise) without altering escape responding to an unconditional stimulus (US, e.g. footshock) (Arnt, 1982; Wadenberg et al., 2001; Natesan et al., 2006). Thus, an antiavoidance responding effect is frequently used as a validated behavioral index of 'antipsychotic' property. Using this model, we found that rats treated with haloperidol (HAL), risperidone (RIS) and olanzapine (OLZ) daily for 7 consecutive days showed a progressive across-session decline in avoidance responding, suggesting that antipsychotics may progressively attenuate the motivational salience of the CS (Wise, 2004; Li et al., 2009). We also found that rats previously treated with HAL and OLZ, and retested under the same dose of drugs after their avoidances re- 
covered to the predrug level, showed fewer avoidances than when they were first tested (Mead and Li, in press). This finding indicates that the interoceptive drug state induced by HAL may also play a role in causing a progressive decline in avoidance across sessions. On the basis of these findings, we proposed that antipsychotics may suppress avoidance responding through a dual action: (i) decreasing the motivational salience of stimuli; (ii) providing an interoceptive drug cue that allows the decreased salience of stimuli to be maintained over time.

In contrast to the well-documented salience attenuation effect of antipsychotics (Fouriezos et al., 1978; Berridge and Robinson, 1998; Dickinson et al., 2000; Wise, 2004; Colpaert et al., 2007), the notion that the drug-induced interoceptive state(s) may be involved in the antipsychotic effects is relatively new, although preclinical studies such as those based on drug discrimination and state-dependent learning have long recognized the distinct drug states induced by typical and atypical antipsychotics (Overton, 1979; Goudie et al., 1998; Porter et al., 2000b; Porter et al., 2005). The primary goal of this study was thus to examine this mechanism further, using a novel drug-drug conditioning paradigm in the CAR model. In this study, we utilized the fact that both HAL (typical APD) and OLZ (atypical APD) disrupt conditioned avoidance responding, whereas chlordiazepoxide (CDP) does not (Sanger, 1985; Li et al., 2004, 2007). If the antipsychotic-induced state is directly involved and critically important in causing a disruption on avoidance responding, pairing CDP with HAL or OLZ through a drug-drug conditioning procedure (Revusky et al., 1989; Taukulis, 1996) should alter the intrinsic property of CDP and engender it to show a disruptive effect on avoidance responding. In Pavlovian terminology, the CDP was considered a CS drug, which signals to an organism that the effects of HAL or OLZ (US) are imminent. Any avoidance-disruptive effect exhibited by CDP after repeated pairing with HAL or OLZ would support the notion that antipsychotic-induced interoceptive state is 'directly' involved in the antipsychotic effect.

As psychotic fear and anxiety disturbances are seen at a relatively high frequency in patients with schizophrenia (Siris, 1994), anxiolytic drugs are frequently combined with antipsychotics in schizophrenic patients (ZumBrunnen and Jann, 1998). This practice of psychotropic polypharmacy has raised some concerns regarding the possible adverse effects of drug-drug interactions (Sandson et al., 2005). This study also allowed us to examine how the repeated pairings of CDP with HAL and OLZ might alter the intrinsic drug efficacy of HAL and OLZ.

\section{Methods}

\section{Subjects}

Male Sprague-Dawley rats (226-250 g upon arrival, Charles River, Portage, Michigan, USA) were housed two per cage, in $48.3 \times 6.7 \times 20.3 \mathrm{~cm}$ transparent polycarbonate cages under 12-h light/ dark conditions (light on between 6:30 am and 6:30 pm). Room temperature was maintained at $21 \pm 11^{\circ} \mathrm{C}$ with a relative humidity of $55-60 \%$. Food and water was freely available. Animals were allowed at least 1 week of habituation to the animal facility before being used in experiments. All procedures were approved by the Institutional Animal Care and Use Committee at the University of Nebraska-Lincoln.

\section{Avoidance conditioning apparatus}

Six identical two-way shuttle boxes, custom designed and manufactured by Med Associates (St. Albans, Vermont, USA), were used. Each box was housed in a ventilated, sound-insulated isolation cubicle $(96.52 \mathrm{~cm}$ wide $\times$ $35.56 \mathrm{~cm}$ deep $\times 63.5 \mathrm{~cm}$ high). Each box was $64 \mathrm{~cm}$ long, $30 \mathrm{~cm}$ high (from grid floor) and $24 \mathrm{~cm}$ wide, and divided into two equal-sized compartments by a white polyvinyl chloride partition with an arch-style doorway $(15 \mathrm{~cm}$ high $\times 9 \mathrm{~cm}$ wide at base). An aluminum hurdle (4 cm high) was placed between the two compartments, so the rats had to jump from one compartment to enter the other. The grid floor consisted of 40 stainless-steel rods, spaced $1.6 \mathrm{~cm}$ apart center to center, through which a scrambled footshock $(0.8 \mathrm{~mA})$ was delivered by a constant current shock generator (Model ENV-410B) and scrambler (Model ENV-412). The location of the rat and motor activity were detected by a set of 16 photobeams (ENV-256-8P) affixed at the bottom of the box $(3.5 \mathrm{~cm}$ above the grid floor). A speaker (ENV 224AMX) mounted on the ceiling of the cubicle, centered above the shuttle box, was used to provide a CS (76 dB white noise). All the training and testing procedures were controlled by Med Associates programs running on a computer. Background noise (approximately $74 \mathrm{~dB}$ ) was provided by a ventilation fan affixed at the top corner of each isolation cubicle.

\section{Drugs}

The injection solutions of HAL $(5 \mathrm{mg} / \mathrm{ml}$ ampoules, Sabex Inc., Boucheville, Quebec, Canada) and CDP (SigmaAldrich, St Louis, Missouri, USA) were obtained by mixing drugs with sterile water. OLZ (Toronto Research Chemical Inc., Canada) was dissolved in 1.5\% glacial acetic acid in distilled water. HAL and OLZ were administered s.c., whereas CDP was administered intraperitoneally. The doses of HAL $(0.05 \mathrm{mg} / \mathrm{kg})$ and OLZ $(1.0 \mathrm{mg} /$ $\mathrm{kg}$ ) and their injection route were chosen based on (i) our previous work showing that at the chosen doses, HAL and OLZ injected s.c. produce a comparable progressive across-session decline in avoidance responding ( $\mathrm{Li}$ et al., 2007); and (ii) rat brain $D_{2}$ receptor occupancy data showing that both drugs give rise to clinically comparable levels of D2 occupancy $(65-80 \%)$ (Kapur et al., 2003). The choice of CDP dose $(10 \mathrm{mg} / \mathrm{kg})$ and its route of injection was based on the findings showing that (i) CDP (10 mg/ $\mathrm{kg}$ ) is ineffective in disrupting avoidance responding ( $\mathrm{Li}$ et al., 2004, 2007); (ii) CDP at this dose is effective in several aversively conditioned paradigms, such as Pavlov- 
ian fear conditioning and passive avoidance responding (Klint, 1991; Joordens et al., 1998); and (iii) at this dose, CDP produces a powerful internal drug cue (Colpaert, 1986).

Experiment 1: effects of repeated chlordiazepoxide and haloperidol pairing on avoidance responding to chlordiazepoxide and haloperidol

The experiment comprised of the following three phases: avoidance training, drug-drug conditioning, and drug testing.

\section{Avoidance training phase}

Forty-two rats were first handled and habituated to the avoidance conditioning apparatus for 2 days (30 min/ day), and then trained for 10 consecutive days to acquire robust conditioned avoidance responding (> 70\% avoidance trials). Each training session consisted of 30 discrete trials. Every trial was started by presenting white noise (CS, $76 \mathrm{~dB}$ ) for $10 \mathrm{~s}$, followed by a continuous footshock (US, $0.8 \mathrm{~mA}$, maximum $5 \mathrm{~s}$ ) on the grid floor. If a subject moved from one compartment into the other within the $10 \mathrm{~s}$ of CS presentation, the shock was prevented, and this shuttling response was recorded as 'avoidance' (a twoway avoidance). If the rat remained in the same compartment for more than $10 \mathrm{~s}$ and made a crossing upon receiving the footshock, this response was recorded as 'escape.' If the rat did not respond during the entire $5 \mathrm{~s}$ presentation of the shock, the trial was terminated and 'escape failure' was recorded. Intertrial intervals varied randomly between 30 and $60 \mathrm{~s}$.

\section{Drug conditioning phase}

At the end of the training phase, rats $(n=32)$ that had reached the training criterion $(\geq 70 \%$ avoidance in each of the last two sessions) were used in the drug conditioning phase. They were randomly assigned to one of four groups. On day 1, each group was given a double injection of one of the following combinations: CDP + vehicle $(\mathrm{VEH})(n=8), \mathrm{VEH}+\mathrm{HAL}(n=7), \mathrm{CDP}+\mathrm{HAL}(n=7)$, and $\mathrm{VEH}+\mathrm{VEH}(n=10)$. The first injection (CDP $10.0 \mathrm{mg} /$ $\mathrm{kg}$, or sterile water, $1.0 \mathrm{ml} / \mathrm{kg}$, i.p.) was given $15 \mathrm{~min}$ before the second injection (HAL $0.05 \mathrm{mg} / \mathrm{kg}$, or sterile water, $1.0 \mathrm{ml} / \mathrm{kg}$, s.c.). One hour after the second injection, rats were placed in the avoidance conditioning boxes and tested. This time interval between CDP and HAL (15 min) was determined so that there was sufficient time for the drug effects of HAL and CDP to overlap and produce a robust drug-drug conditioning effect, given the half-life of CDP at 4-6 h (Koechlin et al., 1965) and HAL at about $1.5 \mathrm{~h}$ (Cheng and Paalzow, 1992). A similar kind of drug-drug conditioning arrangement had been used by Taukulis and Brake (1989). On day 2, rats in the CDP $+\mathrm{VEH}, \mathrm{VEH}+\mathrm{HAL}$, and $\mathrm{CDP}+\mathrm{HAL}$ groups received a single injection of HAL, CDP, and VEH, respectively, whereas the Behavioral mechanisms of antipsychotic action Li et al. $3 \mathrm{VEH}+\mathrm{VEH}$ group received a double injection of CDP and HAL separated by 15 min. Immediately after the injections, rats were returned to their home cages. No avoidance test was done on this day. The pur- pose of giving rats the drug treatments on day 2 and not testing them was to ensure that every rat received the same drug treatment (all rats had CDP, HAL, and VEH), although in different contexts (e.g. home cage vs. CAR boxes) and with different drug injection intervals (15 min vs. $24 \mathrm{~h}$ ), so that the specific drug-drug conditioning effect on avoidance behavior could be assessed. On day 3, all rats were untreated and unhandled. This 3-day drug conditioning cycle repeated for seven times over a 21day period, after which all rats were re-trained drug-free in two consecutive sessions to bring back a high level of avoidance responding.

\section{Drug-testing phase}

The drug-testing phase started $24 \mathrm{~h}$ after the last retraining session. Rats were first injected with CDP (10.0 mg/ $\mathrm{kg}$, i.p.) and tested $75 \mathrm{~min}$ later. The next day, rats were retrained drug-free, and 1 day later, tested again under HAL [0.05 mg/kg, subcutaneously (s.c.), - $60 \mathrm{~min}]$. For both drug tests, the same conditioned avoidance procedure was used except that only the CS was presented in the 30 trials. No shock US was ever presented. The following figure illustrates the general experimental procedure (Figure 1).

Experiment 2: effects of repeated chlordiazepoxide and olanzapine pairing on avoidance responding to chlordiazepoxide and olanzapine

This experiment was identical to experiment 1 except that HAL was replaced by OLZ. Forty-two rats were used, of which 30 reached learning criterion. They were then randomly assigned to one of the following four groups: $\mathrm{CDP}+\mathrm{VEH}(n=6), \mathrm{VEH}+\mathrm{OLZ}(n=8), \mathrm{CDP}+\mathrm{OLZ}(n=9)$, and $\mathrm{VEH}+\mathrm{VEH}(n=7)$, and were subjected to the seven sessions of drug conditioning and two sessions of drug testing (the CDP test followed by the OLZ test).

Experiment 3: reexamining the effects of repeated chlordiazepoxide and haloperidol pairing on avoidance responding to chlordiazepoxide and haloperidol

As the CDP + HAL (experiment 1) and CDP + OLZ pairing (experiment 2) produced different results, we reexamined the effects of repeated CDP and HAL pairing on avoidance responding to CDP and HAL. Twenty rats that had experienced the same white noise and footshock in a Pavlovian fear-conditioning paradigm were used. It should be noted that none of the rats were ever exposed to any drug before this experiment and that there was at least a 2-week window between the previous experiment and this one (unpublished experiment). The basic procedure was the same as the one used in the previous two experiments. First, all rats were trained in 10 avoidance conditioning sessions. At the end of the training Figure 2 phase, 15 rats reached the learning criterion and were randomly assigned to two groups: CDP + HAL $(n=8)$ and VEH+HAL $(n=7)$. They were then subjected to the seven sessions of drug conditioning and two sessions of drug testing (the CDP test followed by the HAL test). 
Fig. 1

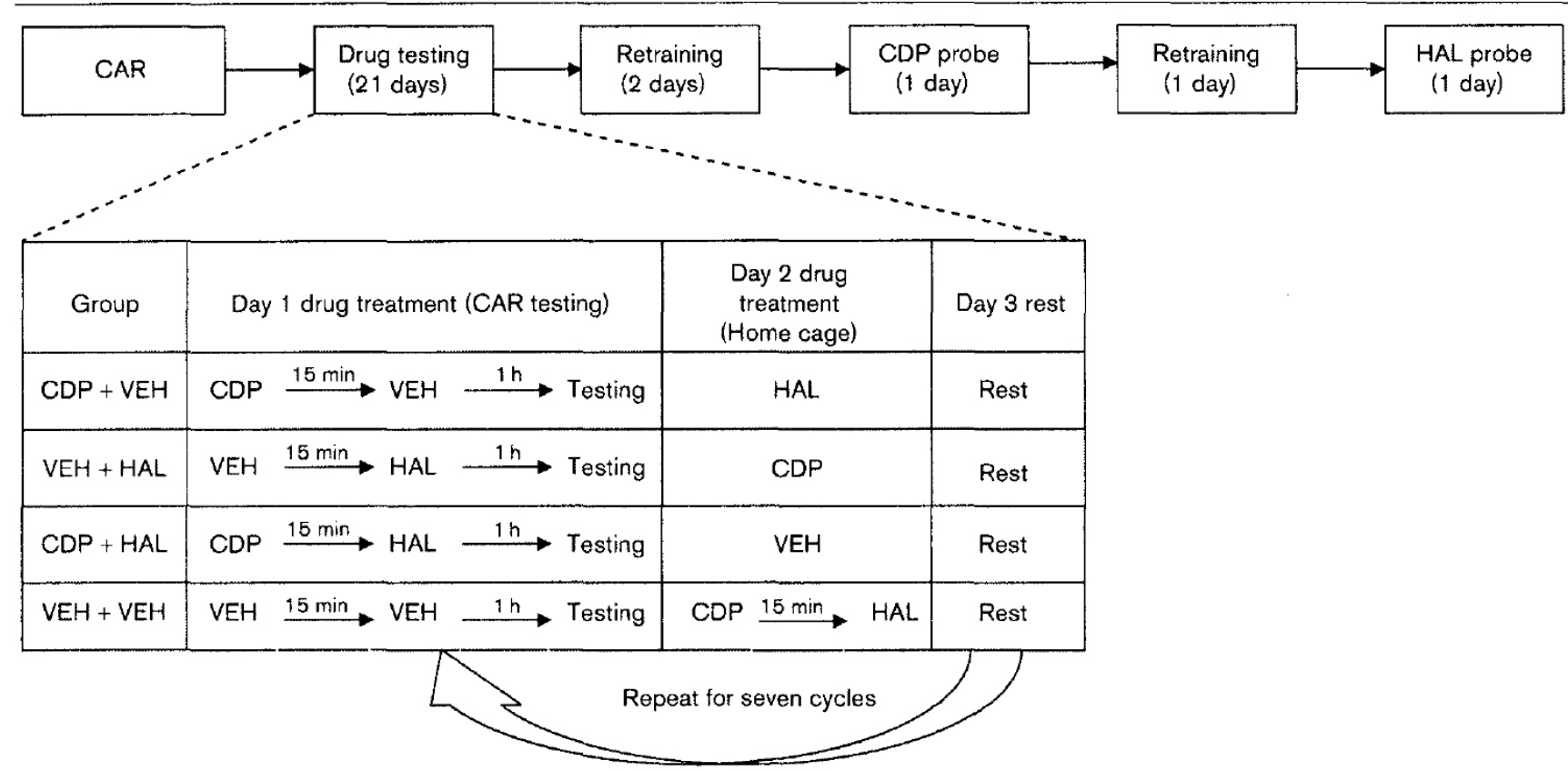

A schematic depiction of the experimental procedure in experiment 1. CAR, conditioned avoidance response; CDP, chlordiazepoxide; HAL, haloperidol; VEH, vehicle.

\section{Statistics}

The main dependent variable was the number of avoidance responses (expressed as mean \pm SEM). Data from the drug-drug conditioning phase were first analyzed using a repeated-measures analysis of variance (ANOVA) with treatments (i.e. four groups) as a between-subjects $\mathrm{CDP}+\mathrm{VEH}(n=8)$ factor and the test sessions (i.e. seven drug sessions) CDP + HAL $(n=7) \mathrm{VEH}+\mathrm{VEH}(n=10)$ $\mathrm{VEH}+\mathrm{HAL}(n=7)$ as a within-subjects factor, followed by post-hoc Tukey's honestly significant difference test to detect the group differences. If a significant group difference was detected, one-way ANOVAs were then used to specify the difference for each drug session. Data from the drug-testing phase were analyzed separately using one-way ANOVAs, followed by Tukey's test. A conventional two-tailed level of significance at the $5 \%$ level was required.

\section{Results}

Experiment 1: effects of repeated chlordiazepoxide and haloperidol pairing on avoidance responding to chlordiazepoxide and haloperidol

Figure 2 shows the number of avoidance responses made by the rats in the four groups during the seven
Fig. 2

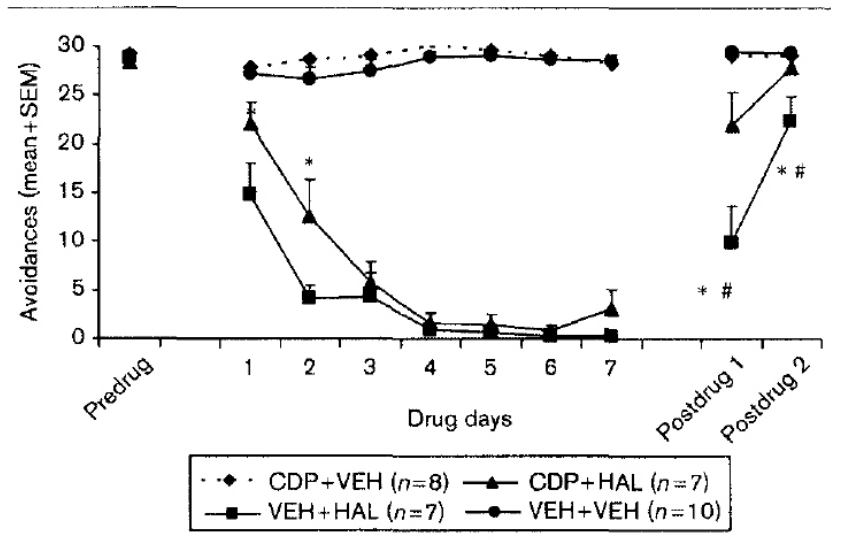

Number of avoidance responses made by the rats in the four groups during the seven drug conditioning sessions and two drug-free retraining sessions from experiment 1. Repeated haloperidol (HAL) treatment significantly disrupted avoidance responding across the seven daily test sessions. This effect was attenuated by chlordiazepoxide (CDP) in the first two sessions. Rats that received the combination of CDP and HAL treatment during the conditioning phase recovered faster than those that only received $\mathrm{HAL}$ when the treatment was stopped. Repeated CDP treatment by itself had no effect on avoidance responding. $* P<0.05$ for comparisons between the two HAL groups. " $P<0.05$ for comparisons between the vehicle $(V E H)+H A L$ and the VEH + VEH group.

drug conditioning sessions and two drug-free retraining sessions. The two HAL groups (e.g. the CDP + HAL and $\mathrm{VEH}+\mathrm{HAL}$ ) showed a progressive across-session decrease in avoidance responding under drug and a quick 
recovery when the treatment was stopped. The other two groups (e.g. the $\mathrm{CDP}+\mathrm{VEH}$ and $\mathrm{VEH}+\mathrm{VEH}$ ) maintained a high level of avoidance responding throughout the entire drug conditioning phase. For the seven drug conditioning sessions, a two-way ANOVA ('treatments' x 'sessions') showed a significant effect of 'treatments' $\left[F_{(3,28)}=\right.$ $322.85, P<0.001]$, 'sessions' $\left[F_{(6,168)}=28.04, P<0.001\right]$, and a significant 'treatments' $\times$ 'sessions' interaction $\left[F_{(18,168)}=\right.$ 15.173, $P<0.001]$. Post-hoc Tukey tests revealed that the $\mathrm{CDP}+\mathrm{HAL}$ and VEH + HAL groups were significantly different from the CDP + VEH and VEH + VEH groups (all $P$ values $<0.001$ ). Interestingly, the CDP + HAL group also differed significantly from the VEH + HAL group $(P$ $=0.045)$. Individual one-way ANOVA revealed that on the first two drug conditioning days, the CDP + HAL rats displayed higher numbers of avoidance responses than the rats in the VEH + HAL group (day 1: $P<0.05$; day 2: $P<0.05$ ), indicating that CDP may have attenuated the HAL effect, at least at the early stage of paired drug treatment. This attenuation was also reflected in the two

Fig. 3

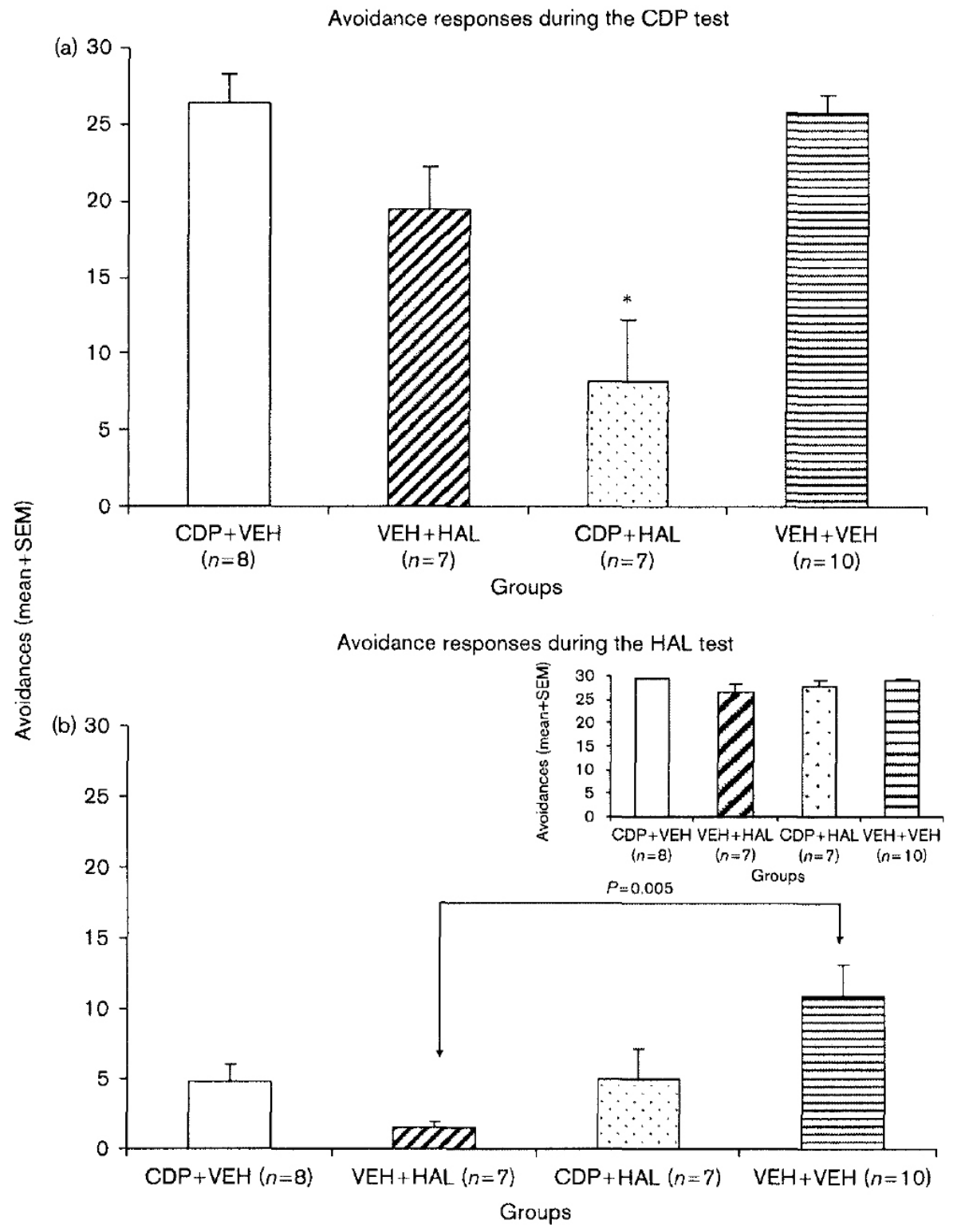

Number of avoidance responses during the chlordiazepoxide (CDP) test (a) and haloperidol (HAL) test (b) from experiment 1. (a) CDP significantly inhibited avoidance responding in the CDP + HAL group during the CDP test ( ${ }^{*} P<0.05$ for post-hoc group comparisons with other three groups). (b) HAL significantly inhibited avoidance responding in all four groups, but to a lesser extent in the vehicle (VEH) + VEH group. The graph in (b) depicts the avoidance responses during the retraining session between the two drug tests. No significant group difference was detected during this session. 
subsequent retraining sessions, as the CDP + HAL group reinstated avoidance responding much faster than the $\mathrm{VEH}+\mathrm{HAL}$ group (CDP + HAL vs. VEH + HAL: day 1: $P<0.01$; day 2: $P<0.05)$. Furthermore, the CDP + HAL group showed no significant difference when compared with the CDP + VEH and VEH + VEH groups (all $P$ values $>0.09$ ), whereas the VEH + HAL did (all $P$ values < 0.01).

Figure $3 \mathrm{a}$ shows the number of avoidance responses during the CDP test. Both the CDP + VEH and VEH + VEH groups exhibited a high level of avoidance responding (the average was 26.4 and 25.7 avoidances, respectively), as did the $\mathrm{VEH}+\mathrm{HAL}$ group (mean number: 19.4), even though there was no shock (only white noise) present during this test. This finding was consistent with the data from the drug conditioning phase, showing that CDP itself has no effect on avoidance responding. In contrast, the CDP + HAL group exhibited the lowest avoidance responses (8.1). One-way ANOVA revealed that the $\mathrm{CDP}+\mathrm{HAL}$ group was significantly different from the other three groups (all $P$ values $<0.025$ ), strongly suggesting that CDP produced a significant inhibition of avoidance responding. In other words, CDP 'acquires' a HALlike property (e.g. disrupting avoidance responding) after being repeatedly paired with HAL. Prior CDP + HAL pairing in the absence of avoidance testing (e.g. the $\mathrm{VEH}$ + VEH group) did not change its property.

After a retraining session [pre-HAL session: no group difference was detected, $F_{(3,28)}=2.16, P=0.12$, Figure $\left.3 b\right]$, all rats were tested for their avoidance responses under HAL in a CS-only session (Figure 3b). In comparison with the pre-HAL session, avoidance responding was apparently lower in all groups. A $4 \times 2$ repeated-measures ANOVA ('treatment' $\times$ 'sessions') showed a significant effect of 'treatment' $\left[F_{(3,28)}=5.34, P<0.005\right]$, 'sessions' $\left[F_{(1,28)}=640.48, P<0.001\right]$, and a significant 'treatment' $x$ 'sessions' interaction $\left[F_{(3,28)}=3.45, P<0.05\right]$. One-way ANOVA focusing on the HAL test session revealed no significant group difference except between the $\mathrm{VEH}+$ HAL and VEH + VEH groups $(P<0.005)$, indicating a strong HAL experience effect consistent with our previous finding ( $\mathrm{Li}$ et al., 2007). More importantly, no significant group difference was detected between the $\mathrm{VEH}+$ HAL and CDP + HAL groups, indicating that the efficacy of HAL had not been altered even after being repeatedly paired with CDP.

Experiment 2: effects of repeated chlordiazepoxide and olanzapine pairing on avoidance responding to chlordiazepoxide and olanzapine

Figure 4 shows the number of avoidance responses made by the rats in the four groups during the seven drug conditioning sessions and two drug-free retraining sessions. Similar to what was seen in experiment 1 , the two OLZ-treated groups (e.g. the CDP + OLZ and VEH + OLZ) showed a progressive across-session decrease in avoidance responding under drug and a quick recovery when OLZ treatment was stopped. The other two groups (e.g. the CDP + VEH and $\mathrm{VEH}+\mathrm{VEH}$ ) maintained a high level of avoidance responding throughout the entire drug conditioning phase. For the seven drug conditioning sessions, a two-way ANOVA ('treatments' $\times$ 'sessions') showed a significant effect of 'treatments' $\left[F_{(3,26)}=69.05, P\right.$ $<0.001]$, 'sessions' $\left[F_{(6,156)}=6.91, P<0.001\right]$, and a significant 'treatments' $\times$ 'sessions' interaction $\left[F_{(18,156)}=4.29, P\right.$ $<0.001$ ]. Post-hoc two-group comparisons revealed that both OLZ-treated groups were significantly different from the other two groups (all $P$ values $<0.001$ ), indicating a potentiated inhibitory effect of repeated OLZ treatment on avoidance responding. This potentiated effect appears to be attenuated to an extent by CDP, as the CDP + OLZ group showed less of a decrease than the VEH + OLZ group. Independent samples $t$-tests on each drug conditioning day revealed that there were significant differences between the two groups on day $4(P<0.001)$, day $5(P<0.02)$, and day $6(P<0.05)$.

Figure 5a shows the number of avoidance responses during the CDP test. All four groups showed a comparably high level of avoidance responding. One-way ANOVA did not show any significant group difference $\left[F_{(3,26)}=1.97\right.$, NS], suggesting that CDP given alone or in combination with OLZ did not change its action on avoidance behavior. After a retraining session [pre-OLZ session: no group difference was detected, $F_{(3,26)}=2.77, P=0.061$, Figure 5b],

Fig. 4

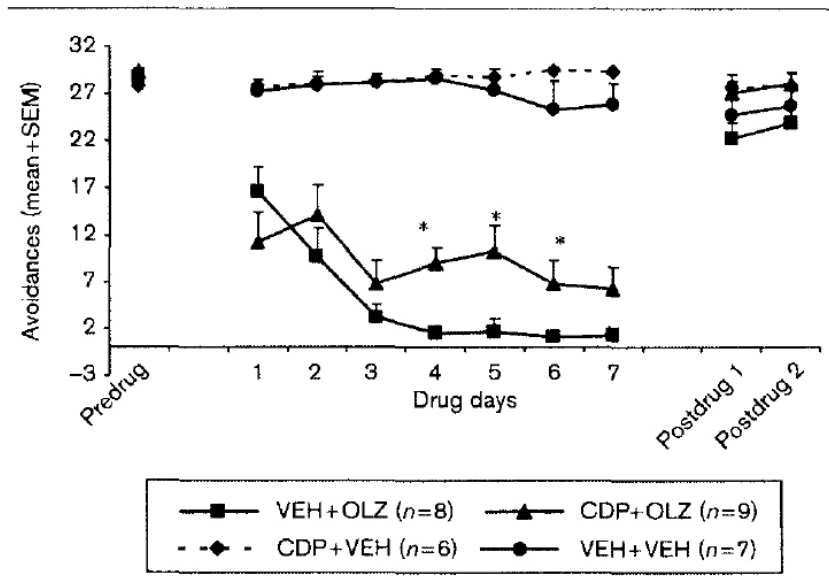

Number of avoidance responses made by the rats in the four groups during the seven drug conditioning sessions and two drug-free retraining sessions from experiment 2. Repeated olanzapine (OLZ) treatment significantly disrupted avoidance responding across the seven daily test sessions. Repeated chlordiazepoxide (CDP) treatment had no effect on avoidance responding. $\mathrm{VEH}$, vehicle. 
Fig. 5

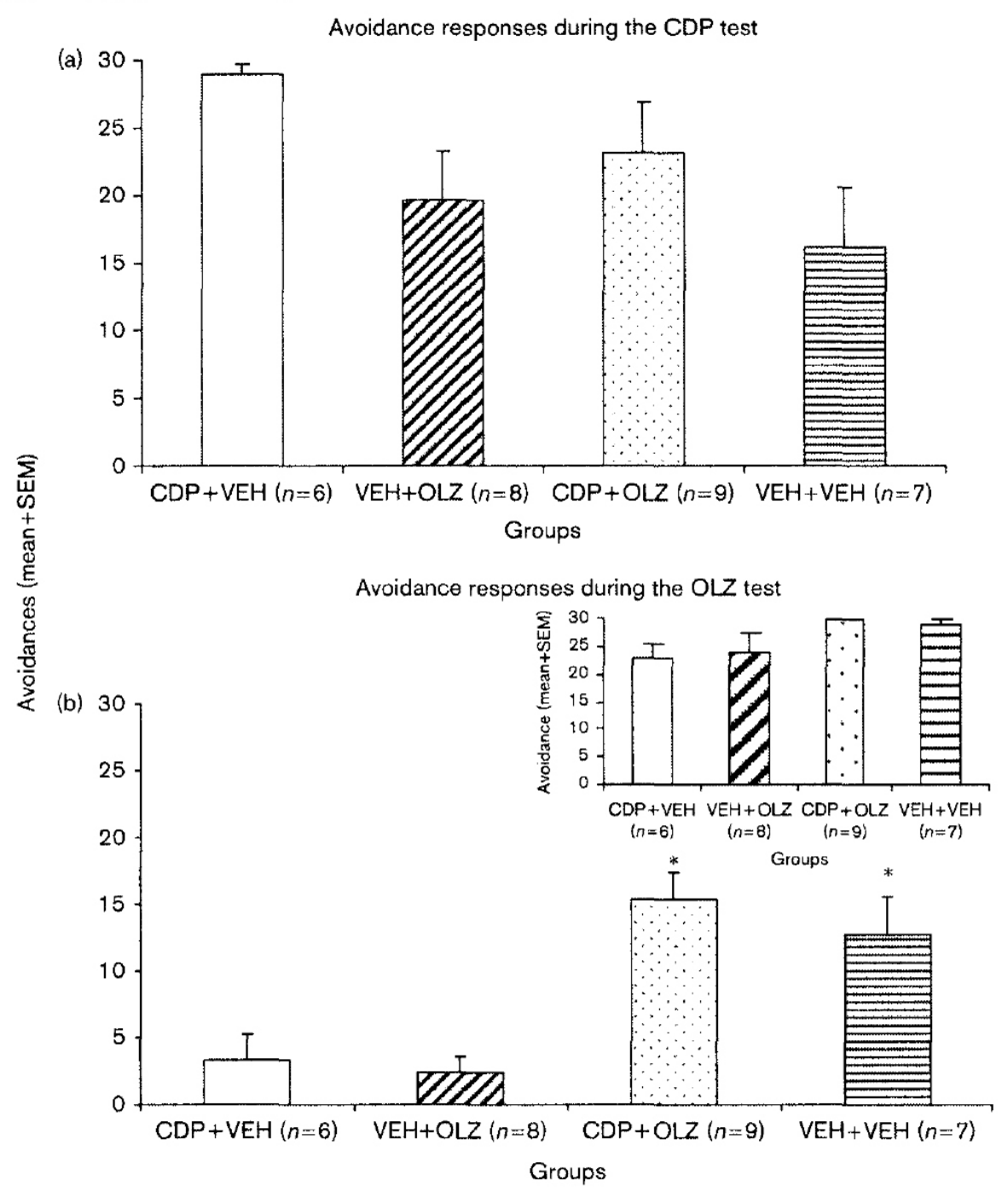

Number of avoidance responses during the chlordiazepoxide (CDP) test (a) and olanzapine (OLZ) test (b) from experiment 2. (a) CDP did not significantly affect avoidance responding during the CDP test. There was no significant group difference. (b) OLZ significantly inhibited avoidance responding, but only in the CDP + vehicle (VEH) and VEH + OLZ group. The two groups treated with the combination of CDP and OLZ during the drug conditioning phase showed less of a decrease in avoidance responding. The graph in (b) depicts the avoidance responses during the retraining session between the two drug tests. No significant group difference was detected during this session.

all rats were tested for their avoidance responses under OLZ in a CS-only session. In comparison with the preOLZ session, avoidance responses were significantly decreased by OLZ, especially in the CDP + VEH and VEH + OLZ groups. A $4 \times 2$ two-way ANOVA ('treatment' $\times$ 'sessions') showed a significant effect of 'treatment' $\left[F_{(3,26)}\right.$ $=8.11, P<0.001]$, 'sessions' $\left[F_{(1,26)}=149.25, P<0.001\right]$, and a significant 'treatment' $\times$ 'sessions' interaction $\left[F_{(3,26)}=\right.$ 5.04, $P<0.01]$. Post-hoc two-group comparisons revealed that the CDP + OLZ and VEH + VEH groups were significantly different from the CDP + VEH and VEH + OLZ groups (all $P$ values $<0.05)$. The $\mathrm{CDP}+\mathrm{VEH}$ group did not differ from the $\mathrm{VEH}+\mathrm{OLZ}$ group. As the CDP + OLZ and $\mathrm{VEH}+\mathrm{VEH}$ groups all received a double drug treatment (e.g. CDP and OLZ pairing), this result suggests that OLZ might lose its antipsychotic action after being repeatedly paired with CDP.

Experiment 3: reexamining the effects of repeated chlordiazepoxide and haloperidol pairing on avoidance responding to chlordiazepoxide and haloperidol

Figure 6 shows the number of avoidance responses during the seven drug conditioning sessions and two drug-free retraining sessions. Both groups showed a progressive across-session decrease in avoidance responding under drug, and a recovery when HAL was stopped. For the seven drug conditioning sessions, a two-way ANOVA ('treatments' $x$ 'sessions') showed a 
significant effect of 'sessions' $\left[F_{(6.78)}=6.36, P<0.001\right]$, but not 'treatments' $\left[F_{(1,13)}=0.048, \mathrm{NS}\right]$, or 'treatments' $\times$ 'sessions' interaction $\left[F_{(6,78)}=0.806, N S\right]$. During the two subsequent retraining sessions, it appeared that the CDP + HAL group reinstated avoidance behavior much faster than the VEH + HAL group and had higher mean numbers of avoidances on both days. This group difference was significant on the first day $(P<0.05)$, but failed to reach a significant level on the second day.

The pattern was reversed on the CDP test (Figure 7a). The CDP + HAL group showed many fewer avoidances than the VEH + HAL group, and this difference was statistically significant $[t(13)=3.00, P<0.01]$. This result confirmed the finding from experiment 1 and supported the notion that CDP might 'acquire' an antipsychotic property after being repeatedly paired with HAL.

After a retraining session [pre-HAL session: no group difference was detected, $t(13)=-1.82, N S$, Figure $7 b]$, all rats were tested for their avoidance responses under HAL in a CS-only session (Figure 7b). As can be seen in Figure $7 \mathrm{~b}$, in comparison with the pre-HAL session, avoidance responding was significantly decreased by HAL $\left[F_{(1,13)}=\right.$ 173.26, $P<0.001]$. There was no significant difference between groups $\left[F_{(1,13)}=2.49, \mathrm{NS}\right]$, indicating that the efficacy of HAL was not altered even if it had been repeatedly paired with CDP.

\section{Discussion}

In the three experiments, we used a novel drug-drug conditioning paradigm and examined the role of anti-

Fig. 6

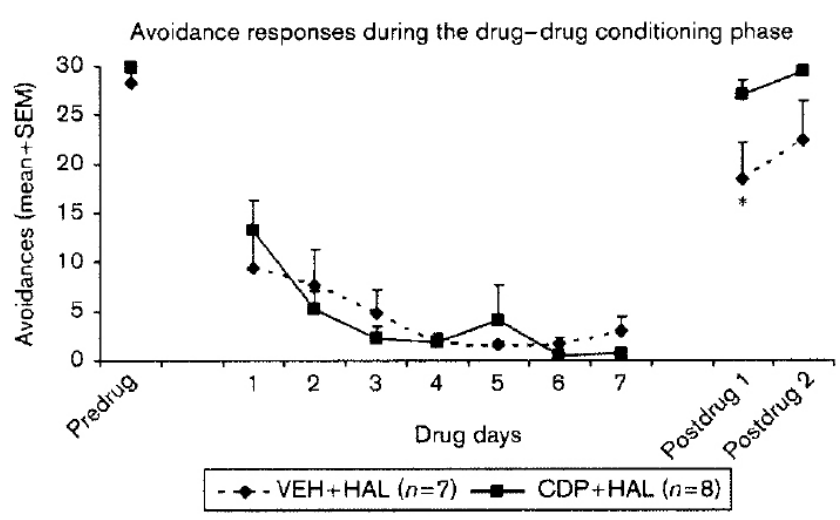

Number of avoidance responses made by the rats in the two groups during the seven drug conditioning sessions and two drug-free retraining sessions from experiment 3 . Repeated haloperidol (HAL) treatment significantly disrupted avoidance responding across the seven daily test sessions. Rats that received the combination of chlordiazepoxide (CDP) and HAL treatment during the conditioning phase recovered faster than those that only received HAL when the treatment was stopped. ${ }^{*} P<0.05$ for comparisons between the two groups. $\mathrm{VEH}$, vehicle.
Fig. 7

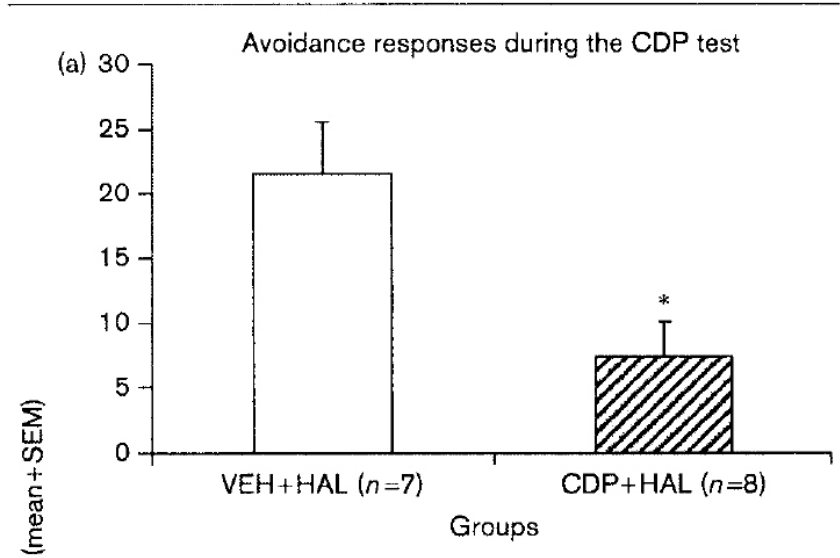

Avoidance responses during the HAL test

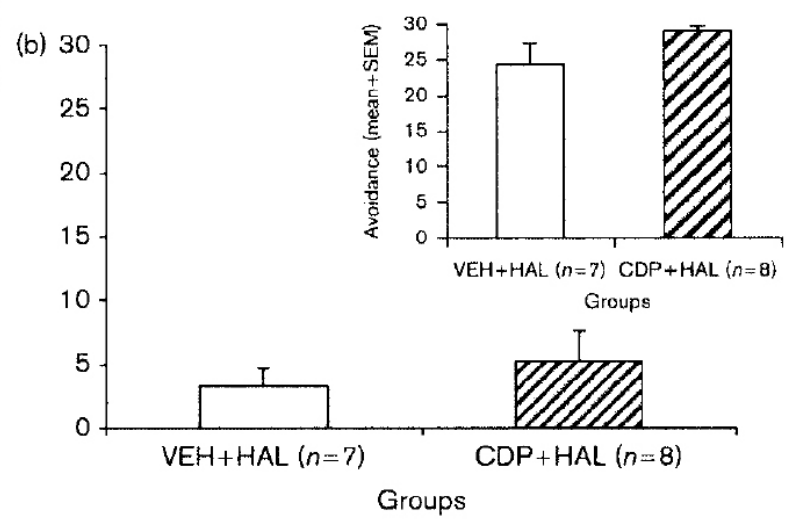

Number of avoidance responses during the chlordiazepoxide (CDP) test (a) and haloperidol (HAL) test (b) from experiment 3. (a) CDP significantly inhibited avoidance responding in the CDP + HAL group during the CDP test, ${ }^{*} P<0.05$. (b) HAL significantly inhibited avoidance responding both groups. The graph in (b) depicts the avoidance responses during the retraining session between the two drug tests. No significant group difference was detected during this session. $\mathrm{VEH}_{\text {, vehicle. }}$

psychotic-induced interoceptive state in the therapeutic effects of antipsychotic treatment. Results from experiments 1 and 3 suggest that the HAL-induced interoceptive state may be involved in its disruptive effect on avoidance responding, as evidenced by the finding showing that CDP + HAL pairing produced an anti-avoidance (e.g. antipsychotic-like) drug activity in CDP. This 'acquired' HAL activity of CDP is attributed to specific drug-drug conditioning with CDP functioning as the drug CS, and HAL as the drug US (Taukulis and Brake, 1989). It is not simply because of pharmacological effects of the drugs, as no such effect was found in two control groups (the CDP + VEH and VEH + HAL), even though they received the same numbers of CDP and HAL injections separated by $24 \mathrm{~h}$. We also showed that, to induce the anti-avoidance effect in CDP, CDP + HAL pairing had to occur within the context of avoidance testing. The same pairing in the home cage (the VEH + VEH group) did not change the drug activity of CDP, indicating an important 
interaction between drug treatment and targeted behavior as well as the direct involvement of HAL-induced drug state in the disruption of avoidance responding.

Unexpectedly, we did not find the same effect with CDP + OLZ pairing from experiment 2. CDP + OLZ pairing did not change the drug activity of CDP on avoidance responding. However, it did change the efficacy of OLZ, making it less effective in disrupting avoidance behavior when it was tested alone. This effect is because of drugdrug conditioning, as the control groups without conditioning (the CDP + VEH and VEH + OLZ) did not show such an effect. In addition, the contexts within which the CDP + OLZ conditioning occurred were not critical because even the drug pairing in the home cage achieved a similar effect (Figure 5b). Overall, the present findings reveal an interesting 'double dissociation' between the effect of CDP pairing with typical antipsychotic HAL and atypical OLZ. CDP + HAL pairing changed the drug activity of CDP, but did not change that of HAL. CDP exhibited an acquired antiavoidance effect after being repeatedly paired with HAL. In contrast, CDP + OLZ pairing changed the drug activity of OLZ, but not that of CDP. OLZ became less effective in disrupting avoidance behavior after repeated pairing.

This study provides additional evidence showing that the HAL-induced interoceptive state is related to its antiavoidance effect, a finding consistent with our previous work (Li et al., 2007; Mead and Li, in press). The differential effect of CDP + HAL and CDP + OLZ pairing is surprising, given the fact that both HAL and OLZ are equally efficacious in the treatment of psychosis (Lieberman et al., 2003) and share a similar molecular mechanism in blocking dopamine $\mathrm{D}_{2}$ receptors (Kapur and Seeman, 2000). At the chosen doses, they also produced a comparable level of avoidance disrupting effect over the seven drug conditioning days (Figs 2 and 4). One possible explanation for the differential effect of CDP + HAL and CDP + OLZ pairing is that HAL and OLZ may induce different interoceptive states that are differently influenced by CDP. Pharmacologically, HAL is primarily a $\mathrm{D}_{2}$ receptor antagonist (Kapur et al., 1996), and it binds 'tightly' to the $\mathrm{D}_{2}$ receptor and dissociates slowly (Kapur and Seeman, 2001), whereas OLZ has a moderate antagonist effect on the $\mathrm{D}_{2}$ receptor but a high antagonist effect on the $5-\mathrm{HT}_{2 \mathrm{~A}}$ serotoninergic, $\mathrm{a}_{1}$ adrenergic, $\mathrm{m}_{1}$ muscarinic, and $\mathrm{H}_{1}$ histaminic receptors (Bymaster et al., 1999; Miyamoto et al., 2005) (Table 1). It is possible that the OLZ state is a compound cue that is mediated by its antagonism against multiple receptors (e.g. $\mathrm{D}_{2^{\prime}}$ 5- $\mathrm{HT}_{2 \mathrm{~A}^{\prime}} \mathrm{a}_{1^{\prime}}$ $\mathrm{m}_{1}$ and $\mathrm{H}_{1}$, etc.), whereas the HAL state is a single cue that is primarily mediated by antagonism against $\mathrm{D}_{2}$ receptors. Drug discrimination studies seem to support this notion (Goudie and Taylor, 1998; Porter et al., 2000a; Cole et al., 2007; Goudie et al., 2007). Using a two-lever drug discrimination paradigm, Porter et al. (2000a) found that the dopamine $\mathrm{D}_{2}$ antagonists chlorpromazine and

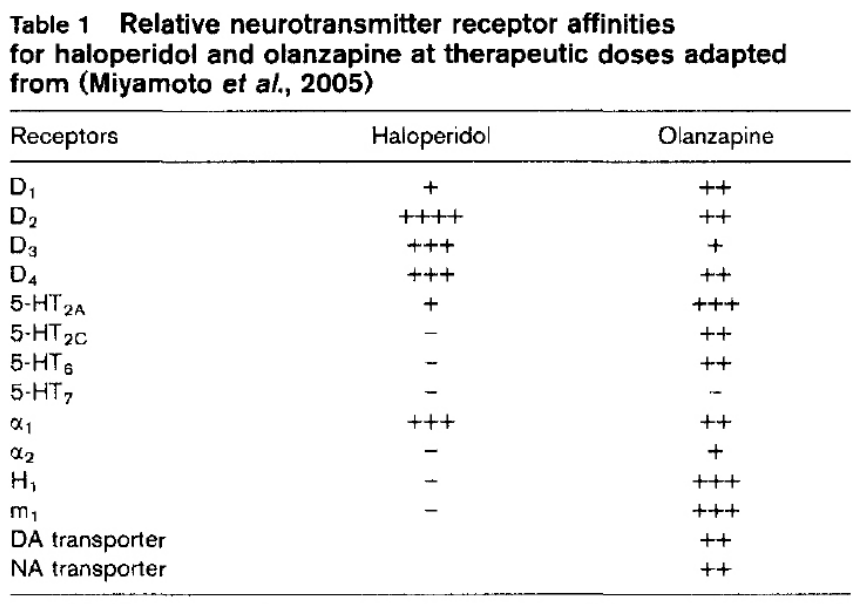

- , minimal to none; + , low; ++ , moderate +++ , high; ++++ , very high

thioridazine substituted for OLZ in producing OLZ-appropriate responding in rats, as did the muscarinic cholinergic antagonist scopolamine and the 5- $\mathrm{HT}_{2 \mathrm{~A} / 2 \mathrm{C}}$ serotonergic antagonist ritanserin. This finding suggests that the antagonism of either dopamine $\mathrm{D}_{2}$ receptors, muscarinic receptors, or $5-\mathrm{HT}_{2 \mathrm{~A} / 2 \mathrm{C}}$ receptors is sufficient to mimic the OLZ-induced interoceptive state. Colpaert et al. (2007) used a two-lever, food-rewarded drug discrimination paradigm and found that HAL was more efficacious than OLZ in inducing 'win-shift' response pattern, possibly because of its strong $\mathrm{D}_{2}$ receptor antagonism. As the 'antipsychotic' action, as well as the antiavoidance effect is thought to be mediated by antagonism against $\mathrm{D}_{2}$ receptors (Wadenberg et al., 2001; Seeman, 2006), the compound cue mediated by multiple receptor actions of OLZ is apparently less effective in bestowing an antipsychotic property to CDP than the single cue mediated by $\mathrm{D}_{2}$ blockade by HAL. This is because other discriminative cues within this compound cue may obscure the 'antipsychotic' cue. Within the same line of reasoning, it is also possible that the differential effects of CDP + HAL and CDP + OLZ pairing is because of the differences between the dopamine $\mathrm{D}_{2}$ receptor bindings of HAL and OLZ. The binding affinity of HAL at $\mathrm{D}_{2}$ receptors is six to seven times greater than that of OLZ (Richelson and Souder, 2000), so although they may share a similar molecular mechanism in blocking $\mathrm{D}_{2}$ receptors, they are not equally efficacious at this site. This distinct molecular binding profile of OLZ opens up the possibility that the discrepant findings represent a pharmacological effect between CDP and OLZ that was not present between CDP and HAL.

Another unexpected finding is that repeated concurrent CDP and OLZ treatment attenuated the antiavoidance effect of OLZ (Figure 5b), but not HAL (Figure 3b 
and Figure $7 \mathrm{~b}$ ) in the drug-alone testing, implying that the antipsychotic efficacy of OLZ, but not HAL, could be potentially attenuated by CDP in the clinic. One clinical report (Wolkowitz et al., 1989) and one preclinical report (Keller et al., 1976) seem to suggest that benzodiazepines may augment the drug effects of typical antipsychotics during the combined drug treatment. Our results did not show such an effect. Owing to limited research on this issue, it is premature to draw a definite conclusion. Future work with more vigorous controls and a wide selection of different types of benzodiazepines and antipsychotics is needed.

Besides its contribution to understanding the behavioral mechanisms of antipsychotics, this study is important because it also provides an approach to study drugdrug interactions in the treatment of schizophrenia. Most schizophrenic patients are treated with multiple psychotherapeutic drugs, such as antipsychotics, selective serotonin reuptake inhibitors, and benzodiazepines to control their diverse symptoms and comorbid anxiety and depression (ZumBrunnen and Jann, 1998). One recent report found that concurrent prescriptions for anxiolytic medications with antipsychotics grew by more than two-thirds from 1995 to 1999 in the state of New Hampshire (Clark et al., 2002). This practice of psychotropic polypharmacy has raised some concerns regarding the efficacy, costs, and possible adverse effects of drug-drug interactions (Alfaro, 2001; Sandson et al., 2005; Rupnow et al., 2007). However, because current clinical data come mostly from case reports and limited uncontrolled studies, it is difficult to assess the extent and nature of drug-drug interactions in schizophrenia (ZumBrunnen and Jann, 1998) and determine their advantages or disadvantages. Our findings that the antiavoidance efficacy of HAL is actually attenuated by CDP during the early treatment phase (experiment 1 , although not confirmed in experiment 3 ) and the long-term antiavoidance efficacy of OLZ is also attenuated by CDP seem to suggest that cautions need to be taken in monitoring the clinical responses of patients during the early stage of combined drug treatment and when benzodiazepines are discontinued.

This present study is also important because it extends research utilizing a Pavlovian Drug-drug conditioning paradigm in the following two directions. First, it introduces a new behavioral model to assess associative conditioning involving two drug cues. In many drug conditioning studies, conditional responses are usually some basic physiological or simple reactive behaviors, such as drug-induced thermic effects, heart rate, stomach emptying, muscle relaxation, or taste aversions (Wilkin et al., 1982; Revusky et al., 1989; Davey and Biederman, 1991; Reilly and Revusky, 1992; Biederman and Davey, 1993). This study shows that even instrumental conditioned active motor behavior can be used as a valid index to evaluate the conditioned drug effect. Second, it introduces a new approach to examine the effects of drug-drug condi- tioning. In many drug conditioning studies, the drug conditioning effect is often indexed by some change in one or more of the properties of the CS drug (Taukulis, 1996). For example, in a series of studies on the diazepam-HAL or diazepam-chlorpromazine conditioning (Taukulis and Brake, 1989; Taukulis et al., 1992), the drug conditioning was evidenced by the changed drug properties of diazepam, such as enhanced hypothermia, diminished muscle relaxation, and enhanced anxiolytic effect. As rightly pointed out by Taukulis (1996), this approach occasionally posits a challenge in the explanation for the drug conditioning phenomenon, because the specific unconditional effects of the 'signaled' drug (drug US) have not always been specified in advance. In this study, the conditioning effect was seen in the newly 'acquired' antipsychotic property in CDP, which is not an intrinsic drug property of CDP, and can only be attributed to the unconditioned effect of HAL. This approach provides an unequivocal demonstration of the drug-drug conditioning effect.

In summary, our results show that the HAL-induced interoceptive state is an important behavioral mechanism responsible for the maintenance of its antiavoidance effect and possibly antipsychotic effect over time. Concurrent use of CPD with antipsychotics, especially with OLZ, may cause a long-term attenuation of the antiavoidance effect of OLZ through a drug-drug interaction mechanism. The model introduced in this study may be useful in delineating behavioral mechanisms of antipsychotic action and assessing polypharmacy involving drug-drug conditioning in the treatment of schizophrenia.

\section{Acknowledgements}

The authors thank Mr Trevor Gregath for help on experiment 1. This study was funded in part by a support from the Nebraska Tobacco Settlement Biomedical Research Development Funds, and NARSAD Young Investigator Award to M.L.

\section{References}

Alfaro CL (2001). Emerging role of drug interaction studies in drug development: the good, the bad, and the unknown. Psychopharmacol Bull 35: 80-93.

Arnt J (1982). Pharmacological specificity of conditioned avoidance response inhibition in rats: inhibition by neuroleptics and correlation to dopaminereceptorblockade.ActaPharmacolToxicol(Copenh)51:321-329.

Berridge KC, Robinson TE (1998). What is the role of dopamine in reward: hedonic impact, reward learning, or incentive salience? Brain Res Brain Res Rev 28: 309-369.

Biederman GB, Davey VA (1993). Antisickness conditioning using a nausea-producing nondrug cue. Behav Neurosci 107: 215-217.

Bymaster FP, Nelson DL, DeLapp NW, Falcone JF, Eckols K, Truex LL, et al. (1999). Antagonism by olanzapine of dopamine $\mathrm{D}_{1^{\prime}}$, serotonin $_{2^{\prime}}$ muscarinic, histamine $\mathrm{H}_{1}$ and alpha, ${ }_{1}$-adrenergic receptors in vitro. Schizophr Res 37: 107-122.

Cheng YF, Paalzow LK (1992). Linear pharmacokinetics of haloperidol in the rat. Biopharm Drug Dispos 13: 69-76.

Clark RE, Bartels SJ, Mellman TA, Peacock WJ (2002). Recent trends in antipsychotic combination therapy of schizophrenia and schizoaffective disorder: implications for state mental health policy. Schizophr Bull 28: 75-84.

Cole JC, Field M, Sumnall HR, Goudie AJ (2007). Potentiation of olanzapine substitution in rats discriminating clozapine by the $\mathrm{D}_{2 / 3}$ agonist quinpirole. Behav Pharmacol 18: 185-190.

Colpaert FC (1986). A method for quantifying state-dependency with chlordiazepoxide in rats. Psychopharmacology (Berl) 90: 144-146. 
Colpaert F, Koek W, Kleven M, Besnard J (2007). Induction by antipsychotics of win-shift in the drug discrimination paradigm. J Pharmacol Exp Ther 322: 288-298.

Davey VA, Biederman GB (1991). Methodological issues in drug-drug conditioning in rats: nonassociative factors in heart rate and avfail. Behav Neurosci 105: 850-859.

Dickinson A, Smith J, Mirenowicz J (2000). Dissociation of Pavlovian and instrumental incentive learning under dopamine antagonists. Behav Neurosci 114: 468-483.

Fouriezos G, Hansson P, Wise RA (1978). Neuroleptic-induced attenuation of brain stimulation reward in rats. J Comp Physiol Psychol 92: 661-671.

Goudie A, Taylor A (1998). Comparative characterisation of the discriminative stimulus properties of clozapine and other antipsychotics in rats. Psychopharmacology (Berl) 135: 392-400.

Goudie AJ, Smith JA, Taylor A, Taylor MA, Tricklebank MD (1998). Discriminative stimulus properties of the atypical neuroleptic clozapine in rats: tests with subtype selective receptor ligands. Behav Pharmacol 9: 699-710.

Goudie AJ, Cooper GD, Cole JC, Sumnall HR (2007). Cyproheptadine resembles clozapine in vivo following both acute and chronic administration in rats. J Psychopharmacol 21: 179-190.

Joordens RJ, Hijzen TH, Olivier B (1998). The anxiolytic effect on the fearpotentiated startle is not due to a non-specific disruption. Life Sci 63: 2,227-2,232.

Kapur S (2003). Psychosis as a state of aberrant salience: a framework linking biology, phenomenology, and pharmacology in schizophrenia. Am J Psychiatry 160: 13-23.

Kapur S, Seeman P (2000). Antipsychotic agents differ in how fast they come off the dopamine $\mathrm{D}_{2}$ receptors. Implications for atypical antipsychotic action. J Psychiatry Neurosci 25: 161-166.

Kapur S, Seeman P (2001). Does fast dissociation from the dopamine d(2) receptor explain the action of atypical antipsychotics?: a new hypothesis. Am J Psychiatry 158: 360-369.

Kapur S, Mamo D (2003). Half a century of antipsychotics and still a central role for dopamine $\mathrm{D}_{2}$ receptors. Prog Neuropsychopharmacol Biol Psychiatry 27: 1,081-1,090.

Kapur S, Remington G, Jones C, Wilson A, DaSilva J, Houle S, Zipursky R (1996). High levels of dopamine $\mathrm{D}_{2}$ receptor occupancy with low-dose haloperidol treatment: a PET study. Am J Psychiatry 153: 948-950.

Kapur S, VanderSpek SC, Brownlee BA, Nobrega JN (2003). Antipsychotic dosing in preclinical models is often unrepresentative of the clinical condition: a suggested solution based on in vivo occupancy. J Pharmacol Exp Ther 305: 625-631.

Keller HH, Schaffner R, Haefely W (1976). Interaction of benzodiazepines with neuroleptics at central dopamine neurons. Naunyn Schmiedebergs Arch Pharmacol 294: 1-7.

Klint T (1991). Effects of 8-OH-DPAT and buspirone in a passive avoidance test and in the elevated plus-maze test in rats. Behav Pharmacol 2: 481-489.

Koechlin BA, Schwartz MA, Krol G, Oberhansli W (1965). The metabolic fate of C14-labeled chlordiazepoxide in man, in the dog, and in the rat. J Pharmacol Exp Ther 148: 399-411.

Li M, Parkes J, Fletcher PJ, Kapur S (2004). Evaluation of the motor initiation hypothesis of APD-induced conditioned avoidance decreases. Pharmacol Biochem Behav 78: 811-819.

Li M, Fletcher PJ, Kapur S (2007). Time course of the antipsychotic effect and the underlying behavioral mechanisms. Neuropsychopharmacology 32: 263-272.

Li M, He W, Mead A (2009). Olanzapine and risperidone disrupt conditioned avoidance responding in phencyclidine-pretreated or amphetamine-pretreated rats by selectively weakening motivational salience of conditioned stimulus. Behav Pharmacol 20: 84-98.

Lieberman JA, Tollefson G, Tohen M, Green AI, Gur RE, Kahn R, et al. (2003). Comparative efficacy and safety of atypical and conventional antipsychotic drugs in first-episode psychosis: a randomized, double-blind trial of olanzapine versus haloperidol. Am J Psychiatry 160: 1,396-1,404.

Lieberman JA, Stroup TS, McEvoy JP, Swartz MS, Rosenheck RA, Perkins DO, et al. (2005). Effectiveness of antipsychotic drugs in patients with chronic schizophrenia. N Engl J Med 353: 1,209-1,223.

Mead A, Li M. Avoidance-suppressing effect of antipsychotic drugs is progressively potentiated after repeated administration: an interoceptive drug state mechanism. J Psychopharmacol (in press).

Miller R (1987). The time course of neuroleptic therapy for psychosis: role of learning processes and implications for concepts of psychotic illness. Psychopharmacology (Berl) 92: 405-415.

Miyamoto S, Duncan GE, Marx CE, Lieberman JA (2005). Treatments for schizophrenia: a critical review of pharmacology and mechanisms of action of antipsychotic drugs. Mol Psychiatry 10: 79-104.

Natesan S, Reckless GE, Nobrega JN, Fletcher PJ, Kapur S (2006). Dissociation between in vivo occupancy and functional antagonism of dopamine $\mathrm{D}_{2}$ receptors: comparing aripiprazole to other antipsychotics in animal models. Neuropsychopharmacology 31: 1,854-1,863.

Overton DA (1979). Preclinical measurement of the amount of state-dependent learning produced by psychoactive drugs [proceedings] Psychopharmacol Bull 15: 51-52.

Porter JH, McCallum SE, Varvel SA, Vann RE (2000a). The discriminative stimulus properties of the atypical antipsychotic olanzapine in rats. Psychopharmacology (Berl) 148: 224-233.

PorterJH, VarvelSA, Vann RE, PhilibinSD, Wise LE(2000b). Clozapine discrimination with a low training dose distinguishes atypical from typical antipsychotic drugs in rats. Psychopharmacology (Berl) 149: 189-193.

Porter JH, Prus AJ, Vann RE, Varvel SA (2005). Discriminative stimulus properties of the atypical antipsychotic clozapine and the typical antipsychotic chlorpromazine in a three-choice drug discrimination procedure in rats. Psychopharmacology (Berl) 178: 67-77.

Reilly S, Revusky S (1992). Drug-drug heart rate conditioning in rats: effective USs when pentobarbital is the CS. Pharmacol Biochem Behav 42 633-643.

Revusky S, Davey V, Zagorski M (1989). Heart rate conditioning with pentobarbital as a conditioned stimulus and amphetamine as an unconditioned stimulus. Behav Neurosci 103: 296-307.

Richelson E, Souder T (2000). Binding of antipsychotic drugs to human brain receptors focus on newergeneration compounds. Life Sci68:29-39.

Richtand NM, Welge JA, Logue AD, Keck PE Jr, Strakowski SM, McNamara RK (2007). Dopamine and serotonin receptor binding and antipsychotic efficacy. Neuropsychopharmacology 32: 1,715-1,726.

Rupnow MF, Greenspan A, Gharabawi GM, Kosik-Gonzalez C, Zhu Y, Stahl SM (2007). Incidence and costs of polypharmacy: data from a randomized, double-blind, placebo-controlled study of risperidone and quetiapine in patients with schizophrenia or schizoaffective disorder. Curr Med Res Opin 23: 2,815-2,822.

Sandson NB, Armstrong SC, Cozza KL (2005). An overview of psychotropic drug-drug interactions. Psychosomatics 46: 464-494.

Sanger DJ (1985). The effects of clozapine on shuttle-box avoidance responding in rats: comparisons with haloperidol and chlordiazepoxide. Pharmacol Biochem Behav 23: 231-236.

Seeman P (2000). Antipsychotic drugs, dopamine $\mathrm{D}_{2}$ receptors and schizophrenia. In: Lidow MS, editor. Neurotransmitter Receptors in Actions of Antipsychotic Medications. Boca Raton, Florida: CRC Press LLC; pp. 43-63.

Seeman P (2006). Targeting the dopamine $\mathrm{D}_{2}$ receptor in schizophrenia. Expert Opin Ther Targets 10: 515-531.

Siris SG (1994). Schizophrenia. In: Hirsch SR, Weinberger DR, editors. Schizophrenia: Exploring the Spectrum of Psychosis. Oxford: Blackwell; pp. $128-145$.

Taukulis HK(1996). Pavlovian conditioning to a diazepam cue with yohimbine as the unconditional stimulus. Neurobiol Learn Mem 65: 223-232.

Taukulis HK, Brake LD (1989). Therapeutic and hypothermic properties of diazepam altered by a diazepam-chlorpromazine association. Pharmacol Biochem Behav 34: 1-6.

Taukulis HK, Fillmore MT, Ruggles JL (1992). Neuroleptic-induced changes in the anxiolytic and myorelaxant properties of diazepam in the rat. Pharmacol Biochem Behav 41: 13-21.

Wadenberg ML, Soliman A, VanderSpek SC, Kapur S (2001). Dopamine $\mathrm{D}(2)$ receptor occupancy is a common mechanism underlying animal models of anti-psychotics and their clinical effects. Neuropsychopharmacology 25: 633-641.

Wilkin LD, Cunningham CL, Fitzgerald RD (1982). Pavlovian conditioning with ethanol and lithium: effects on heart rate and taste aversion in rats. J Comp Physiol Psychol 96: 781-790.

Wise RA (2004). Dopamine, learning and motivation. Nat Rev Neurosci 5: 483-494.

Wolkowitz OM, Breier A, Doran A, Lucas P, Kelsoe J, Paul SM, Pickar D (1989). Alprazolam augmentation of neuroleptics in schizophrenia. Am J Psychiatry 146: 1,087-1,088.

Zumbrunnen TL, Jann MW (1998). Drug interactions with antipsychotic agents: incidence and therapeutic implications. CNS Drugs 9: 381-401. 